\title{
Maniobras clínicas en el diagnóstico de la entorsis de tobillo: una revisión de la literatura
}

Clinical test in diagnosis of ankle sprain: a literature review

Laia Sors Tor ${ }^{1}$, Aitor Pérez Morcillo ${ }^{2,3}$, Javier Alfaro Santafé1,2, Carles Escalona Marfil ${ }^{1}$ y Antonio Gómez Bernal $^{1,2}$

'Departamento de Podología, Facultad de Ciencias de la Salud, Universidad de Manresa, España. ${ }^{2}$ Departamento de Investigación Podoactiva. Cuarte, Huesca, España. ${ }^{3}$ Departamento de Podología, Facultad de Ciencias de la Salud, Universidad Católica de Murcia. Guadalupe, Murcia, España.

Palabras clave:

Entorsis de tobillo, lesión de tobillo, test clínicos,

inestabilidad de tobillo.

\section{Resumen}

Introducción: La entorsis de tobillo es la lesión musculoesquelética más común en personas que practican actividades físicas deportivas y de ocio. El objetivo principal de esta revisión de la literatura es enumerar las maniobras clínicas de interés para el diagnóstico de la entorsis de tobillo.

Material y métodos: Búsqueda bibliográfica en cuatro bases de datos (PubMed, Cochrane, Dialnet y Medline). Se tuvieron en cuenta los estudios de los últimos 10 años (desde 2008 hasta 2018) que hablaran de maniobras clínicas y pruebas funcionales. Los términos de búsqueda fueron: "Ankle Sprain", "clinical test", "instability", "biomechanics" y "treatment".

Resultados: Se revisaron un total de 16 artículos a texto completo. Las maniobras clínicas son fiables a la hora de diagnosticar cada tipo de lesión, pudiendo añadir alguna prueba complementaria específica si fuera necesario.

Discusión: La entorsis de tobillo es una lesión muy extensa y que necesita un tratamiento prolongado. Las maniobras clínicas son útiles para valorar el diagnóstico de las estructuras afectadas de la entorsis de tobillo.

Keywords:

Ankle sprain, ankle injury, clinical test, ankle instability.

\begin{abstract}
Introduction: Ankle sprains are among the most frequent musculoskeletal injuries in people who partake in sporting and leisure activities. The primary objective of this systematic review is to describe the clinical tests used in the evaluation of ankle sprains.

Material and methods: Four databases were used to carry out a bibliography search (PubMed, Cochrane, Dialnet y Medline). Studies from the previous 10 years, which dealt with clinical and functional tests, were taken into account. The following search terms were used; 'Ankle Sprain', 'clinical test', 'instability', 'biomechanics' and 'treatment'.

Results: There were reviewed 16 full-text articles. The clinical practices are reliable when diagnosing each type of injury, and allow for the addition of specific complementary tests if necessary.

Discussion: The clinical tests are useful when assessing the diagnosis of the affected structures in ankle sprains. The experience and the technique of the clinician and the design of a standardized protocol are essential for the reliability.
\end{abstract}




\section{INTRODUCCIÓN}

La entorsis, también llamada esguince de tobillo, es la lesión musculoesquelética más común en personas que practican actividades físicas deportivas, recreativas, de ocio, de atención primaria y del departamento de emergencia ${ }^{1-5}$.

Se define como entorsis de tobillo cuando uno o más ligamentos del tobillo están desgarrados o parcialmente desgarrados $^{6}$. Estos, como el resto de ligamentos del cuerpo, sirven para proporcionar estabilidad mecánica, información propioceptiva y movimientos dirigidos por la articulación ${ }^{7}$.

Las lesiones de ligamentos se clasifican por su severidad ${ }^{6,8}$ : - Grado I, leve: ligero estiramiento del ligamento sin desgarre.

- Grado II, moderado: lesiones parciales sin inestabilidad de articulación. Desgarro parcial de los ligamentos, hinchazón moderada, equimosis y sensibilidad.

- Grado III, severo: lesión con rotura completa del ligamento. Severa hinchazón, equimosis y dolor.

La entorsis puede ocurrir por diversos mecanismos de lesión; las lesiones por inversión son el tipo más común y dan como resultado el estiramiento de los ligamentos del lado lateral del pie, comúnmente el ligamento peroneoastragalino anterior y el peroneocalcáno ${ }^{8,9}$; con menos frecuencia los ligamentos mediales, en concreto el ligamento deltoideo ${ }^{2,7,9}$ y la sindesmosis, lesión de la membrana interósea que une tibia y peroné, produciéndose de forma aislada o asociada con una fractura del peroné $e^{9,10}$.

Las lesiones de entorsis por inversión involucran alrededor del $25 \%$ de todas las lesiones del sistema musculoesquelético y el $50 \%$ de todas las lesiones relacionadas con el deporte ${ }^{5}$.

En todo el mundo aproximadamente se produce una entorsis de tobillo por cada 10.000 persona/día y 2 millones de casos agudos cada año. Las personas más jóvenes y atléticas presentan un $30 \%$ de lesiones y el resto de la población general, el $70 \% 5,6,11,12$. Según los diferentes estudios científicos hay una mayor incidencia de entorsis de tobillo en poblaciones más jóvenes y en pacientes de género femenino ${ }^{7,8,10}$.

Los factores de riesgo pueden evaluarse como factores extrínsecos (relacionados con el medio ambiente) y factores intrínsecos (relacionados con la persona) ${ }^{13}$.

Los extrínsecos incluyen cambios ambientales, nivel de juego, carga y cantidad de ejercicio, nivel de entrenamiento, práctica en equipo, posición jugada, condiciones y reglas de juego y agresividad practicada ${ }^{14,15}$.

Los intrínsecos incluyen variaciones anatómicas, déficits de fuerza y musculatura, esguinces anteriores, laxitud articular generalizada, debilidad en la inversión del tobillo, rango limitado de movimiento, género, índice de masa corporal (IMC), control postural, tiempo de reacción retardada y dan más importancia a los cambios biomecánicos relacionados con variaciones anatómicas ${ }^{13}$.

El mayor factor de riesgo intrínseco para la entorsis de tobillo es haber padecido una entorsis anterior ${ }^{11,13,16}$
El diagnóstico y tratamiento adecuado pueden prevenir complicaciones a largo plazo como inestabilidad y rigidez mecánica y cambios degenerativos ${ }^{17}$.

Las características más importantes del examen físico son los signos Celsius: tumefacción, rubor, calor y dolor; incluyendo también el llamado quinto signo o signo de Virchow: pérdida o disminución de la función ${ }^{2,6,17}$.

Un examen físico después de 4-5 días de la lesión proporciona un diagnóstico más eficaz y fiable, ya que en el examen dentro de las 48 horas posteriores al traumatismo, debido a la difusión del lugar de dolor e hinchazón, es difícil diferenciar hematoma de edema y las respectivas pruebas son poco fiables ${ }^{18}$. Alrededor del $60 \%$ de los pacientes con una lesión del ligamento lateral tienen dolor en la palpación a nivel del maléolo medial y en la palpación debido al desgarro de la zona ${ }^{6}$. La capacidad de caminar de nuevo dentro de 48 horas indica un buen pronóstico ${ }^{6,7}$.

Es importante durante el examen físico valorar los movimientos principales del tobillo, flexión plantar, flexión dorsal, inversión y eversión de forma activa (por el paciente) y pasiva (por el examinador) y compararlos con la extremidad sana para determinar cualquier diferencia, ya que el rango de movimiento puede ser reducido como resultado del dolor y la hinchazón ${ }^{17}$.

La resonancia magnética ( $R M)$, la radiografía ( $R x)$ y la ecografía (ECO) son un complemento del examen físico útil en el diagnóstico de las lesiones de tobillo (hueso y partes blandas) ${ }^{6}$.

A través de esta revisión de la literatura se pretende enumerar las maniobras clínicas de interés para el diagnóstico de la entorsis de tobillo, determinar la fiabilidad de las maniobras clínicas para la evaluación de la entorsis de tobillo, clasificar las maniobras según las indicaciones de ejecución debido al estadio del dolor y según diferenciar el modo de ejecución de las maniobras según la estructura valorada.

\section{MATERIAL Y MÉTODOS}

Para la realización de esta revisión de la literatura se realizó una búsqueda bibliográfica donde se consultaron las siguientes bases de datos: PubMed, Cochrane, Dialnet, Medline. Para la selección de los artículos se siguieron las recomendaciones de la metodología PRISMA ${ }^{19,20}$. Las palabras clave utilizadas en la búsqueda de artículos relacionados con las maniobras clínicas en el diagnóstico de la entorsis de tobillo fueron "Ankle AND sprain AND clinical test", "Ankle sprain AND instabiliy AND clinical test", "Ankle sprain AND biomechanics AND clinical test", Ankle AND sprain AND treatment AND clinical test" (Tabla I).

En un primer momento se recuperaron un total de 785 artículos que respondían a los términos de búsqueda usando las combinaciones de palabras clave nombradas anteriormente: 398 fueron excluidos por el título y el resumen por no tener relación directa con el tema, 27 por duplicidad y 271 por fechas de publicación escogiendo publicaciones recientes desde 2008 hasta 2018. De los 89 artículos restantes, tras la aplicación de los criterios de inclusión y de 
exclusión, quedaron un total de 16 artículos para el análisis completo de sus resultados (Figura 1).

Los criterios de inclusión fueron: maniobras clínicas utilizadas en el diagnóstico y evolución de la entorsis de tobillo, determinación de la fiabilidad de las maniobras, diferenciación de maniobras funcionales, de maniobras clínicas en carga o descarga. Y los criterios de exclusión fueron: revisión

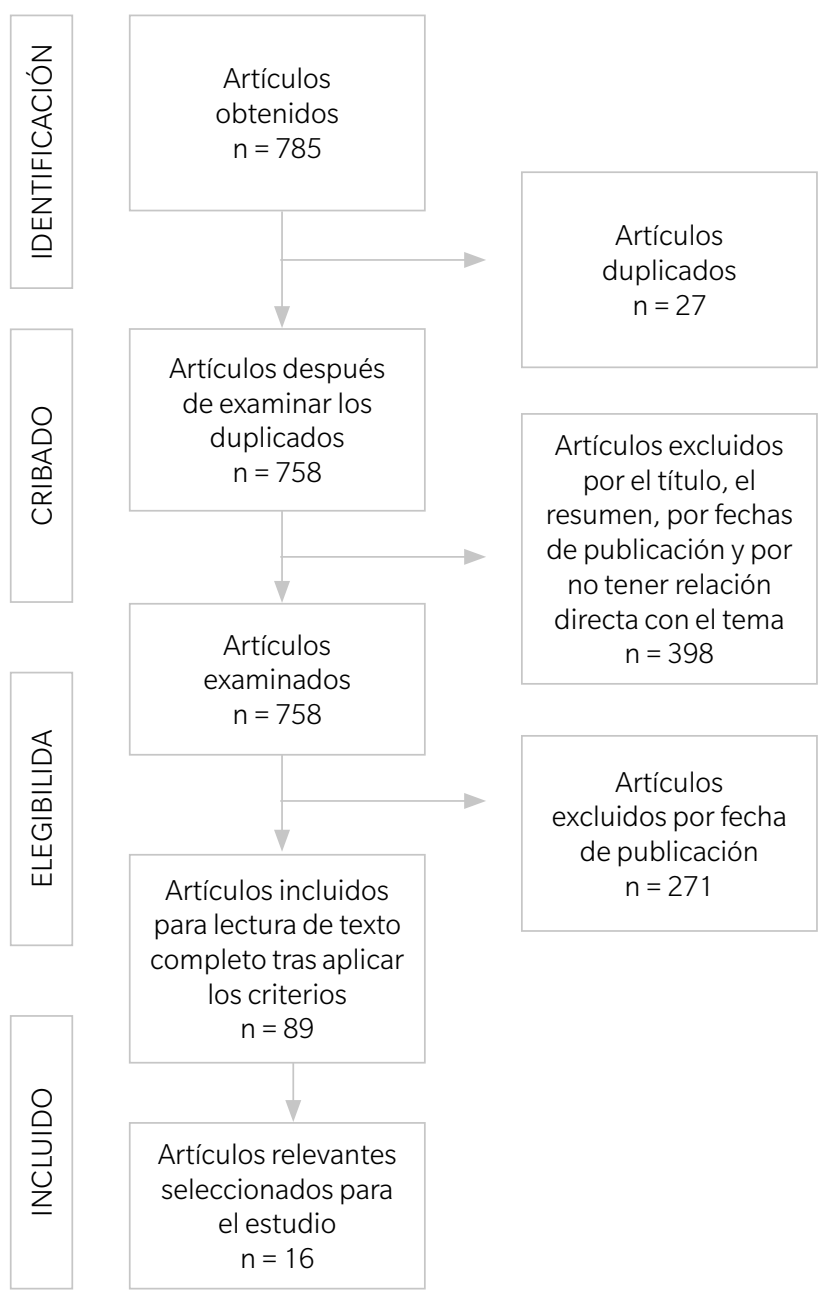

Figura 1. Diagrama de flujo basado en las recomendaciones del método PRISMA para la selección de artículos. sistemática, diagnóstico y evolución a través de aparatos informáticos, publicaciones anteriores al año 2008 valorando los artículos más actuales de los últimos 10 años.

Tras la aplicación de los criterios, esta revisión bibliográfica se ha basado en 16 artículos para el análisis completo de sus resultados. Todos ellos corresponden a los 10 últimos años (desde 2008 hasta 2018) y todos fueron publicados en inglés.

Los artículos seleccionados fueron clasificados siguiendo los niveles de evidencia según la escala de United States Preventive Servies Task Force (USPSTF) ${ }^{21}$.

\section{RESULTADOS}

Se analizaron un total de 16 artículos, todos ellos de los 10 últimos años. Según la escala USPSTF ${ }^{21}$, los niveles de evidencia en 2 de ellos fue $\mathrm{I}^{5,22}$, en 6 fue II-1 ${ }^{23-28}$ y el resto II-2 $2^{29-36}$. Un total de 1337 pacientes fueron analizados (Tabla II).

En la Tabla III se muestra, además del autor, año de publicación, prueba, tipos de prueba de los artículos, la estructura valorada, síntomas, modo de ejecución, la realización y una imagen donde vemos como se realiza cada prueba.

Todos los artículos incluidos en la revisión muestran pruebas que valoran el diagnóstico de diferentes estructuras, clasificándolos cómo pruebas funcionales y maniobras clínicas (Tablas III y IV) (Figura 2).

En la mayoría de los artículos no se especifican los síntomas principales de la lesión $n^{5,26-31,34-36}$ exceptuando algunos de ellos que sí que manifiestan los síntomas principales que padece el paciente $22-25,29,32,33$ (Tabla III).

De las principales pruebas analizadas en cada artículo, las más utilizadas coincidiendo según los diferentes autores son la prueba de Cajón Anterior 5,22,24,29,31,35, prueba de Rotación Externa ${ }^{5,22,31,32,35}$, Star Excursion Balance Test ${ }^{24,26,28,30,33}$ y Squeeze Test ${ }^{5,22,31,32,35}$ (Tabla III).

El resto también son utilizadas con menos frecuencia y algunas de ellas no se repiten entre autores $5,22,24,28,32$.

Prácticamente todos los resultadas muestran una fiabilidad alta (Tabla III) en la aplicación de las maniobras clínicas, pudiendo diagnosticar con la prueba específica el tipo de lesión y de esta forma aplicar el diagnóstico adecuado.

Tabla I. Combinación de palabras clave utilizadas en base de datos.

\begin{tabular}{|c|c|c|c|c|}
\hline & PubMed & Cochrane & Dialnet & Medline \\
\hline Ankle AND sprain AND clinical test & 274 & 4 & 2 & 0 \\
\hline Ankle sprain AND instability AND clinical test & 214 & 2 & 19 & 0 \\
\hline Ankle sprain AND biomechanics AND clinical test & 62 & 0 & 4 & 0 \\
\hline Ankle AND sprain AND Treatment AND clinical test & 193 & 7 & 4 & 0 \\
\hline
\end{tabular}


Tabla II. Resumen de los artículos incluidos y clasificación según niveles de calidad de la evidencia (USPSTF).

\begin{tabular}{|c|c|c|c|c|c|c|}
\hline Autor & Año & Nivel de evidencia & Muestra pacientes & Hombres & Mujeres & Rango de edad \\
\hline Christophe y cols. ${ }^{36}$ & 2009 & II-2 & 29 & 21 & 8 & $18.4-25.2$ \\
\hline Hans y cols. ${ }^{35}$ & 2011 & II-2 & - & - & - & - \\
\hline Christophe y cols. ${ }^{34}$ & 2012 & II-2 & 58 & 38 & 20 & 21.8-24.9 \\
\hline Martin y cols. ${ }^{23}$ & 2012 & II-1 & 53 & - & - & $18-65$ \\
\hline Cory y cols. ${ }^{5}$ & 2014 & I & - & - & - & - \\
\hline Takumi y cols. ${ }^{24}$ & 2014 & II-1 & 30 & - & - & - \\
\hline Alex y cols. ${ }^{22}$ & 2015 & I & - & - & - & - \\
\hline Michel y cols. ${ }^{33}$ & 2015 & II-2 & 40 & 13 & 27 & $18.49-28.01$ \\
\hline Amy y cols. ${ }^{32}$ & 2015 & II-2 & 87 & 67 & 9 & $18.1-31.1$ \\
\hline Lars y cols. ${ }^{31}$ & 2016 & II-2 & 100 & 55 & 41 & $18-59$ \\
\hline Adam y cols. ${ }^{30}$ & 2017 & II-2 & 680 & - & - & - \\
\hline Emily y cols. ${ }^{25}$ & 2017 & II-1 & 50 & 25 & 25 & $18-35$ \\
\hline Jupil y cols. ${ }^{26}$ & 2017 & II-1 & 58 & 26 & 32 & $18-25$ \\
\hline Cynthia y cols. ${ }^{28}$ & 2017 & II-1 & 40 & 11 & 29 & 16.71-28.49 \\
\hline Thomas y cols. ${ }^{27}$ & 2018 & II-1 & 30 & - & - & $18-25$ \\
\hline Cailbhe y cols. ${ }^{29}$ & 2018 & II-2 & 82 & 54 & 28 & $28-65$ \\
\hline
\end{tabular}




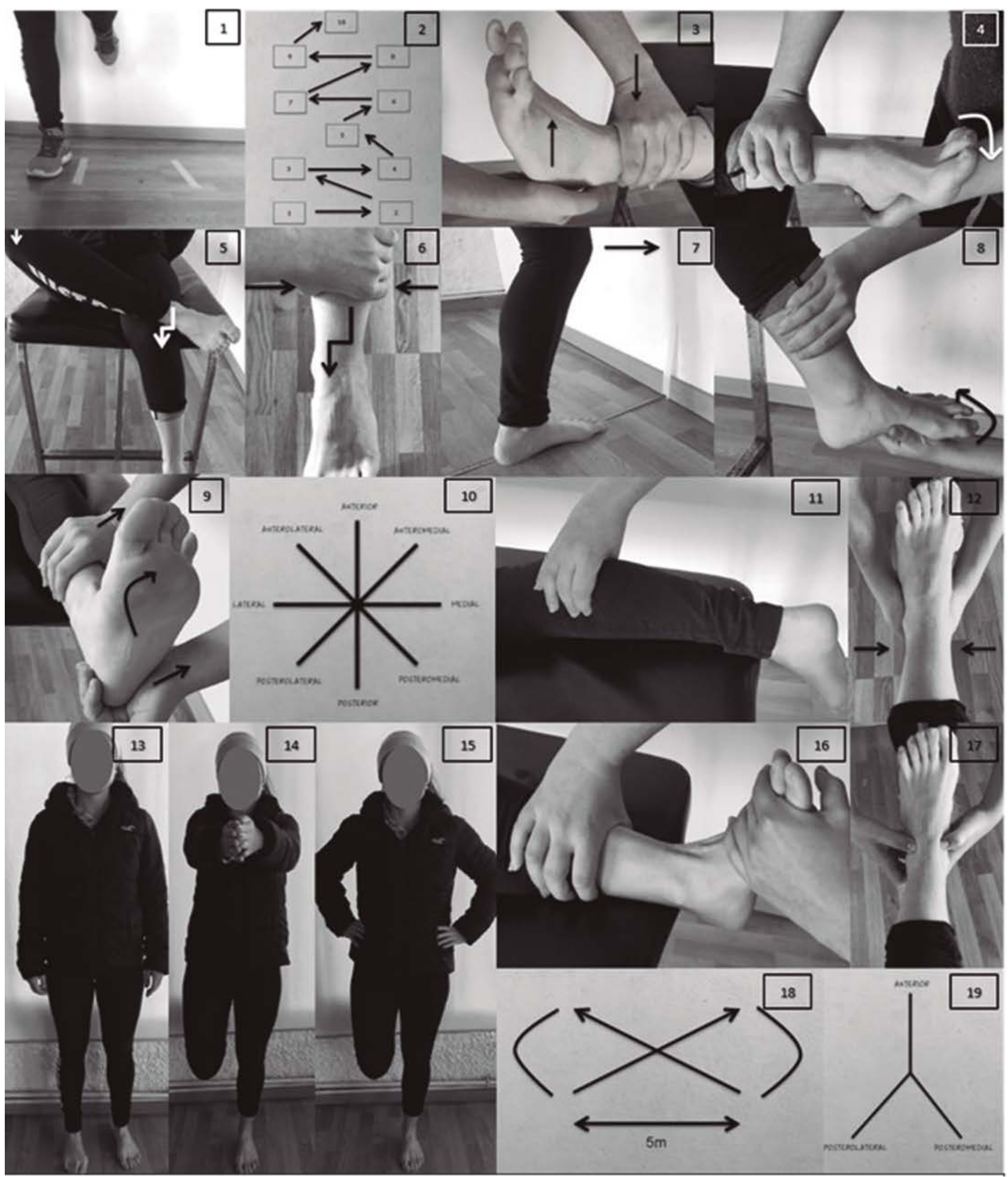

1. Side hop test; 2. Multiple hop test; 3. Cajón anterior; 4. Talar tilt test; 5 . Prueba de pierna cruzada; 6 . Squeeze test; 7. Lunge test; 8. Prueba de rotación externa; 9 . Eversión stress test; 10. Star excursión balance test; 11. Test de Thomsom; 12. Prueba de algodon; 13. Test de Romberg; 14. Foot tilf test; 15. Time in balance, 16. Palpación ligamentosa; 17. Prueba traccion fibular; 18. Eight hop test; 19. Y-Balance test.

Figura 2. Test funcionales y pruebas clínicas analizadas. 
Tabla III. Descripción técnica de los test clínicos y funcionales de los artículos.

\begin{tabular}{|c|c|c|c|c|c|}
\hline $\begin{array}{l}\text { Autor } \\
\text { (año) }\end{array}$ & Test & $\begin{array}{l}\text { Tipo } \\
\text { de test }\end{array}$ & $\begin{array}{l}\text { Esctructura } \\
\text { valorada }\end{array}$ & $\begin{array}{c}\text { Modo } \\
\text { de ejecución }\end{array}$ & Realización \\
\hline $\begin{array}{l}\text { Christophe y cols. } \\
(2009)^{36}\end{array}$ & $\begin{array}{l}\text { Multiple } \\
\text { Hop Test }\end{array}$ & $\begin{array}{l}\text { Test } \\
\text { funcional }\end{array}$ & $\begin{array}{l}\text { No especifica: } \\
\text { inestabilidad } \\
\text { crónica } \\
\text { de tobillo }\end{array}$ & $\begin{array}{l}\text { - Activo } \\
\text { - Carga } \\
\text { - Dinámico }\end{array}$ & $\begin{array}{l}\text { - Saltos unipodales siguiendo } \\
\text { un patrón } \\
\text { - } 3 \text { minutos descanso entre } \\
\text { extremidades }\end{array}$ \\
\hline \multirow{5}{*}{ Hans y cols. ${ }^{35}$} & $\begin{array}{l}\text { Prueba } \\
\text { de cajón } \\
\text { anterior }\end{array}$ & $\begin{array}{l}\text { Maniobra } \\
\text { clínica }\end{array}$ & ATFL & $\begin{array}{l}\text { - Pasivo } \\
\text { - Descarga } \\
\text { - Estático }\end{array}$ & $\begin{array}{l}\text { - Rodilla flexionada } \\
\text { - Tobillo en flexión plantar } \\
\text { - Manipulamos talón desde } \\
\text { posterior a anterior fijando tibia }\end{array}$ \\
\hline & Talar Tilt Test & $\begin{array}{l}\text { Maniobra } \\
\text { clínica }\end{array}$ & $\begin{array}{l}\text { - ATFL } \\
\text { - CFL }\end{array}$ & $\begin{array}{l}\text { - Pasivo } \\
\text { - Descarga } \\
\text { - Estático }\end{array}$ & $\begin{array}{l}\text { - Tobillo neutro } \\
\text { - Talón estable mientras se realiza } \\
\text { inversión de astrágalo y calcáneo }\end{array}$ \\
\hline & $\begin{array}{l}\text { Prueba } \\
\text { de rotación } \\
\text { externa }\end{array}$ & $\begin{array}{l}\text { Maniobra } \\
\text { clínica }\end{array}$ & - Sindesmosis & $\begin{array}{l}\text { - Pasivo } \\
\text { - Descarga } \\
\text { - Estático }\end{array}$ & $\begin{array}{l}\text { - Rodilla flexionada } \\
\text { - Tobillo neutro } \\
\text { - Rotación externa fijando tibia }\end{array}$ \\
\hline & $\begin{array}{l}\text { Squeeze } \\
\text { Test }\end{array}$ & $\begin{array}{l}\text { Maniobra } \\
\text { clínica }\end{array}$ & - Sindesmosis & $\begin{array}{l}\text { - Pasivo } \\
\text { - Descarga } \\
\text { - Estático }\end{array}$ & $\begin{array}{l}\text { - Comprimir tibia y peroné por } \\
\text { encima del punto medio de la } \\
\text { pantorrilla }\end{array}$ \\
\hline & $\begin{array}{l}\text { Prueba } \\
\text { de pierna } \\
\text { cruzada }\end{array}$ & $\begin{array}{l}\text { Maniobra } \\
\text { clínica }\end{array}$ & - Sindesmosis & $\begin{array}{l}\text { - Activo } \\
\text { - Descarga } \\
\text { - Estático }\end{array}$ & $\begin{array}{l}\text { - Pierna a examinar cruzada por } \\
\text { encima de la rótula } \\
\text { - Paciente aplica fuerza en la } \\
\text { pierna cruzada }\end{array}$ \\
\hline $\begin{array}{l}\text { Christophe y cols } \\
(2012)^{34}\end{array}$ & $\begin{array}{l}\text { Multiple } \\
\text { Hop Test }\end{array}$ & $\begin{array}{l}\text { Test } \\
\text { funcional }\end{array}$ & $\begin{array}{l}\text { No especifica: } \\
\text { inestabilidad crónica } \\
\text { de tobillo }\end{array}$ & $\begin{array}{l}\text { - Activo } \\
\text { - Carga } \\
\text { - Dinámico }\end{array}$ & $\begin{array}{l}\text { - Saltos unipodales siguiendo un } \\
\text { patrón } \\
\text { - } 3 \text { minutos descanso entre } \\
\text { extremidades }\end{array}$ \\
\hline $\begin{array}{l}\text { Martin y cols. } \\
(2012)^{23}\end{array}$ & Lunge Test & $\begin{array}{l}\text { Test } \\
\text { funcional }\end{array}$ & $\begin{array}{l}\text { - Gastrocnemios } \\
\text { - Sóleo } \\
\text { - Integridad } \\
\text { ligamentos del } \\
\text { tobillo }\end{array}$ & $\begin{array}{l}\text { - Activo } \\
\text { - Carga } \\
\text { - Estático }\end{array}$ & $\begin{array}{l}\text { - Centro de talón y hallux encima } \\
\text { cinta métrica } \\
\text { - Tocar línea de la pared sin } \\
\text { levantar pie del suelo }\end{array}$ \\
\hline \multirow{5}{*}{ Cory y cols. $^{5}$} & $\begin{array}{l}\text { Prueba } \\
\text { de cajón } \\
\text { anterior }\end{array}$ & $\begin{array}{l}\text { Maniobra } \\
\text { clínica }\end{array}$ & $\begin{array}{l}\text { - Subluxación } \\
\text { anterior del } \\
\text { astrágalo } \\
\text { - ATFL }\end{array}$ & $\begin{array}{l}\text { - Pasivo } \\
\text { - Descarga } \\
\text { - Estático }\end{array}$ & $\begin{array}{l}\text { - Estabilizamos pierna. } \\
\text { - Pie en flexión plantar y en ligera } \\
\text { inversión. } \\
\text { - Aplicamos fuerza anterior en el } \\
\text { talón. }\end{array}$ \\
\hline & Talar Tilt test & $\begin{array}{l}\text { Maniobra } \\
\text { clínica }\end{array}$ & $\begin{array}{l}\text { - Inversión excesiva } \\
\text { del tobillo } \\
\text { - CFL }\end{array}$ & $\begin{array}{l}\text { - Pasivo } \\
\text { - Descarga } \\
\text { - Estático }\end{array}$ & $\begin{array}{l}\text { - Tobillo neutro } \\
\text { - Aplicamos fuerza de inversión } \\
\quad \text { suave al tobillo }\end{array}$ \\
\hline & $\begin{array}{l}\text { Eversión } \\
\text { Stress Test }\end{array}$ & $\begin{array}{l}\text { Maniobra } \\
\text { clínica }\end{array}$ & $\begin{array}{l}\text { - Ligamento } \\
\text { deltoideo }\end{array}$ & $\begin{array}{l}\text { - Pasivo } \\
\text { - Descarga } \\
\text { - Estático }\end{array}$ & $\begin{array}{l}\text { - Pierna colgando de la camilla } \\
\text { - Estabilizamos pierna con una } \\
\text { mano } \\
\text { - Manipulamos el calcáneo en } \\
\text { eversión y haciéndolo rodar } \\
\text { lateralmente }\end{array}$ \\
\hline & $\begin{array}{l}\text { Prueba } \\
\text { de rotación } \\
\text { externa }\end{array}$ & $\begin{array}{l}\text { Maniobra } \\
\text { clínica }\end{array}$ & - Sindesmosis & $\begin{array}{l}\text { - Pasivo } \\
\text { - Descarga } \\
\text { - Estático }\end{array}$ & $\begin{array}{l}\text { - Rodilla flexionada } \\
\text { - Tobillo neutro } \\
\text { - Rotación externa fijando pierna }\end{array}$ \\
\hline & $\begin{array}{l}\text { Squeeze } \\
\text { Test }\end{array}$ & $\begin{array}{l}\text { Maniobra } \\
\text { clínica }\end{array}$ & - Sindesmosis & $\begin{array}{l}\text { - Pasivo } \\
\text { - Descarga } \\
\text { - Estático }\end{array}$ & $\begin{array}{l}\text { - Comprimimos tibia y peroné por } \\
\text { encima del punto medio de la } \\
\text { pantorrilla. }\end{array}$ \\
\hline
\end{tabular}


Tabla III. Descripción técnica de los test clínicos y funcionales de los artículos.

\begin{tabular}{|c|c|c|c|c|c|}
\hline $\begin{array}{l}\text { Autor } \\
\text { (año) }\end{array}$ & Test & $\begin{array}{l}\text { Tipo } \\
\text { de test }\end{array}$ & $\begin{array}{l}\text { Esctructura } \\
\text { valorada }\end{array}$ & $\begin{array}{c}\text { Modo } \\
\text { de ejecución }\end{array}$ & Realización \\
\hline \multirow{4}{*}{$\begin{array}{l}\text { Takumi y cols. } \\
(2014)^{24}\end{array}$} & $\begin{array}{l}\text { Prueba } \\
\text { de cajón } \\
\text { anterior }\end{array}$ & $\begin{array}{l}\text { Maniobra } \\
\text { clínica }\end{array}$ & - ATFL & $\begin{array}{l}\text { - Pasivo } \\
\text { - Descarga } \\
\text { - Estático }\end{array}$ & $\begin{array}{l}\text { - Estabilizamos pierna } \\
\text { - Pie en flexión plantar y en ligera } \\
\text { inversión } \\
\text { - Aplicamos fuerza anterior } \\
\text { en el talón }\end{array}$ \\
\hline & $\begin{array}{l}\text { Test de } \\
\text { Romberg }\end{array}$ & $\begin{array}{l}\text { Test } \\
\text { funcional }\end{array}$ & $\begin{array}{l}\text { No especifica: } \\
\text { inestabilidad crónica } \\
\text { de tobillo }\end{array}$ & $\begin{array}{l}\text { - Activo } \\
\text { - Carga } \\
\text { - Estático }\end{array}$ & $\begin{array}{l}\text { - Paciente de pie con los pies } \\
\text { cercanos con los ojos abiertos } \\
\text { - Se le pide que cierre los ojos } \\
\text { - Comprobar si al cerrar los ojos } \\
\text { pierde equilibrio }\end{array}$ \\
\hline & $\begin{array}{l}\text { Star } \\
\text { Excursion } \\
\text { Balance Test }\end{array}$ & $\begin{array}{l}\text { Test } \\
\text { funcional }\end{array}$ & $\begin{array}{l}\text { No especifica: } \\
\text { inestabilidad crónica } \\
\text { de tobillo }\end{array}$ & $\begin{array}{l}\text { - Activo } \\
\text { - Carga } \\
\text { - Dinámico }\end{array}$ & $\begin{array}{l}\text { - Se forma una estrella con cinta } \\
\text { - Paciente debe mantener el } \\
\text { equilibrio unipodal, mientras } \\
\text { intenta llegar lo más lejos posible } \\
\text { con la otra pierna } \\
\text { - Se realiza en todas las } \\
\text { direcciones }\end{array}$ \\
\hline & $\begin{array}{l}\text { Multiple } \\
\text { Hop Test }\end{array}$ & $\begin{array}{l}\text { Test } \\
\text { funcional }\end{array}$ & $\begin{array}{l}\text { No especifica: } \\
\text { inestabilidad crónica } \\
\text { de tobillo }\end{array}$ & $\begin{array}{l}\text { - Activo } \\
\text { - Carga } \\
\text { - Dinámico }\end{array}$ & $\begin{array}{l}\text { - Saltos unipodales siguiendo un } \\
\text { patrón } \\
\text { - } 3 \text { minutos descanso entre } \\
\text { extremidades }\end{array}$ \\
\hline \multirow{7}{*}{$\begin{array}{l}\text { Aelx y cols. } \\
(2015)^{22}\end{array}$} & $\begin{array}{l}\text { Prueba } \\
\text { de cajón } \\
\text { anterior }\end{array}$ & $\begin{array}{l}\text { Maniobra } \\
\text { clínica }\end{array}$ & - ATFL & $\begin{array}{l}\text { - Pasivo } \\
\text { - Descarga } \\
\text { - Estático }\end{array}$ & $\begin{array}{l}\text { - Rodilla y tobillo flexionados } \\
\text { - Estabilizamos tibia distal } \\
\text { - Aplicamos fuerza anterior } \\
\text { en el talón }\end{array}$ \\
\hline & Talar Tilt Test & $\begin{array}{l}\text { Maniobra } \\
\text { clínica }\end{array}$ & $\begin{array}{l}\text { - } \text { ATFL } \\
\text { - CLF }\end{array}$ & $\begin{array}{l}\text { - Pasivo } \\
\text { - Descarga } \\
\text { - Estático }\end{array}$ & $\begin{array}{l}\text { - Rodilla y tobillo flexionados } \\
\text { - Inversión desde la parte } \\
\text { posterior del talón }\end{array}$ \\
\hline & $\begin{array}{l}\text { Test de } \\
\text { Thompson }\end{array}$ & $\begin{array}{l}\text { Maniobra } \\
\text { clínica }\end{array}$ & - Tendón Aquiles & $\begin{array}{l}\text { - Pasivo } \\
\text { - Descarga } \\
\text { - Estático }\end{array}$ & $\begin{array}{l}\text { - Paciente en decúbito prono } \\
\text { - Comprimimos la pantorrilla } \\
\text { de la pierna afectada }\end{array}$ \\
\hline & $\begin{array}{l}\text { Prueba de } \\
\text { rotación } \\
\text { externa }\end{array}$ & $\begin{array}{l}\text { Maniobra } \\
\text { clínica }\end{array}$ & - Sindesmosis & $\begin{array}{l}\text { - Pasivo } \\
\text { - Descarga } \\
\text { - Estático }\end{array}$ & $\begin{array}{l}\text { - Tobillo neutro } \\
\text { - Movimiento de eversión } \\
\text { estabilizando tibia y peroné }\end{array}$ \\
\hline & $\begin{array}{l}\text { Squeeze } \\
\text { Test }\end{array}$ & $\begin{array}{l}\text { Maniobra } \\
\text { clínica }\end{array}$ & - Sindesmosis & $\begin{array}{l}\text { - Pasivo } \\
\text { - Descarga } \\
\text { - Estático }\end{array}$ & $\begin{array}{l}\text { - Comprimimos tibia y peroné } \\
\text { a nivel de la pantorrilla }\end{array}$ \\
\hline & $\begin{array}{l}\text { Prueba de } \\
\text { algodón }\end{array}$ & $\begin{array}{l}\text { Maniobra } \\
\text { clínica }\end{array}$ & - Sindesmosis & $\begin{array}{l}\text { - Pasivo } \\
\text { - Descarga } \\
\text { - Estático }\end{array}$ & $\begin{array}{l}\text { - Tobillo neutro } \\
\text { - Aplicamos fuerzas mediales } \\
\quad \text { y laterales en el astrágalo }\end{array}$ \\
\hline & $\begin{array}{l}\text { Prueba de } \\
\text { traducción } \\
\text { fibular }\end{array}$ & $\begin{array}{l}\text { Maniobra } \\
\text { clínica }\end{array}$ & - Sindesmosis & $\begin{array}{l}\text { - Pasivo } \\
\text { - Descarga } \\
\text { - Estático }\end{array}$ & $\begin{array}{l}\text { - Palpación cara anterior } \\
\text { del peroné } \\
\text { - Comparar con la otra extremidad } \\
\text { para ver diferencias significativas }\end{array}$ \\
\hline $\begin{array}{l}\text { Michael y cols. } \\
(2015)^{33}\end{array}$ & $\begin{array}{l}\text { Star } \\
\text { Excursion } \\
\text { Balance Test }\end{array}$ & $\begin{array}{l}\text { Test } \\
\text { funcional }\end{array}$ & $\begin{array}{l}\text { - Rango de } \\
\text { movimiento en } \\
\text { flexión plantar } \\
\text { - Sensación cutánea } \\
\text { plantar } \\
\text { - Déficit del control } \\
\text { postural }\end{array}$ & $\begin{array}{l}\text { - Pasivo } \\
\text { - Descarga } \\
\text { - Estático }\end{array}$ & $\begin{array}{l}\text { - Mantener base estable sobre } \\
\text { una extremidad } \\
\text { - Extremidad contralateral } \\
\text { se realiza el alcance máximo } \\
\text { de las marcas }\end{array}$ \\
\hline
\end{tabular}


Tabla III. Descripción técnica de los test clínicos y funcionales de los artículos.

\begin{tabular}{|c|c|c|c|c|c|}
\hline $\begin{array}{l}\text { Autor } \\
\text { (año) }\end{array}$ & Test & $\begin{array}{l}\text { Tipo } \\
\text { de test }\end{array}$ & $\begin{array}{l}\text { Esctructura } \\
\text { valorada }\end{array}$ & $\begin{array}{c}\text { Modo } \\
\text { de ejecución }\end{array}$ & Realización \\
\hline \multirow{3}{*}{$\begin{array}{l}\text { Amy y cols. } \\
(2015)^{32}\end{array}$} & $\begin{array}{l}\text { Prueba de } \\
\text { rotación } \\
\text { externa }\end{array}$ & $\begin{array}{l}\text { Maniobra } \\
\text { clínica }\end{array}$ & - Sindesmosis & $\begin{array}{l}\text { - Pasivo } \\
\text { - Descarga } \\
\text { - Estático }\end{array}$ & $\begin{array}{l}\text { - Rodilla flexionada } \\
\text { - Tobillo en dorsiflexión } \\
\text { - Aplicamos rotación externa }\end{array}$ \\
\hline & $\begin{array}{l}\text { Squeeze } \\
\text { Test }\end{array}$ & $\begin{array}{l}\text { Maniobra } \\
\text { clínica }\end{array}$ & - Sindesmosis & $\begin{array}{l}\text { - Pasivo } \\
\text { - Descarga } \\
\text { - Estático }\end{array}$ & $\begin{array}{l}\text { - Pierna colgando camilla } \\
\text { - Comprimimos tibia y peroné a } \\
\text { nivel de la pantorrilla }\end{array}$ \\
\hline & $\begin{array}{l}\text { Palpación } \\
\text { ligamentosa }\end{array}$ & $\begin{array}{l}\text { Test } \\
\text { funcional }\end{array}$ & $\begin{array}{l}\text { - Ligamentos del } \\
\text { tobillo }\end{array}$ & $\begin{array}{l}\text { - Pasivo } \\
\text { - Descarga } \\
\text { - Estático }\end{array}$ & $\begin{array}{l}\text { - Palpamos diferentes ligamentos } \\
\text { del pie } \\
\text { - Paciente tiene que informar de } \\
\text { dolor }\end{array}$ \\
\hline \multirow{5}{*}{$\begin{array}{l}\text { Lars y cols. } \\
(2016)^{31}\end{array}$} & $\begin{array}{l}\text { Prueba de } \\
\text { cajón } \\
\text { anterior }\end{array}$ & $\begin{array}{l}\text { Maniobra } \\
\text { clínica }\end{array}$ & - ATFL & $\begin{array}{l}\text { - Pasivo } \\
\text { - Descarga } \\
\text { - Estático }\end{array}$ & $\begin{array}{l}\text { - Tobillo en flexión plantar } \\
\text { - Manipulamos talón desde } \\
\quad \text { posterior a anterior fijando tibia }\end{array}$ \\
\hline & $\begin{array}{l}\text { Squeeze } \\
\text { Test }\end{array}$ & $\begin{array}{l}\text { Maniobra } \\
\text { clínica }\end{array}$ & Sindesmosis & $\begin{array}{l}\text { - Pasivo } \\
\text { - Descarga } \\
\text { - Estático }\end{array}$ & $\begin{array}{l}\text { - Comprimimos tibia y peroné por } \\
\text { la altura de la pantorrilla }\end{array}$ \\
\hline & $\begin{array}{l}\text { Prueba de } \\
\text { rotación } \\
\text { externa }\end{array}$ & $\begin{array}{l}\text { Maniobra } \\
\text { clínica }\end{array}$ & Sindesmosis & $\begin{array}{l}\text { - Pasivo } \\
\text { - Descarga } \\
\text { - Estático }\end{array}$ & $\begin{array}{l}\text { - Rodilla flexionada } \\
\text { - Tobillo neutro } \\
\text { - Rotación externa fijando tibia }\end{array}$ \\
\hline & $\begin{array}{l}\text { Prueba de } \\
\text { algodón }\end{array}$ & $\begin{array}{l}\text { Maniobra } \\
\text { clínica }\end{array}$ & Sindesmosis & $\begin{array}{l}\text { - Pasivo } \\
\text { - Descarga } \\
\text { - Estático }\end{array}$ & $\begin{array}{l}\text { - Tobillo neutro } \\
\text { - Aplicamos fuerzas mediales y } \\
\quad \text { laterales en el astrágalo }\end{array}$ \\
\hline & $\begin{array}{l}\text { Prueba de la } \\
\text { pierna } \\
\text { cruzada }\end{array}$ & $\begin{array}{l}\text { Maniobra } \\
\text { clínica }\end{array}$ & Sindesmosis & $\begin{array}{l}\text { - Activo } \\
\text { - Descarga } \\
\text { - Estático }\end{array}$ & $\begin{array}{l}\text { - Pierna a examinar cruzada por } \\
\text { encima de la rótula. } \\
\text { - Paciente aplica fuerza en la } \\
\text { pierna cruzada. }\end{array}$ \\
\hline \multirow{4}{*}{$\begin{array}{l}\text { Adam y cols. } \\
(2017)^{30}\end{array}$} & $\begin{array}{l}\text { Multiple } \\
\text { Hop Test }\end{array}$ & $\begin{array}{l}\text { Test } \\
\text { funcional }\end{array}$ & $\begin{array}{l}\text { No especifica: } \\
\text { inestabilidad crónica } \\
\text { de tobillo }\end{array}$ & $\begin{array}{l}\text { - Activo } \\
\text { - Carga } \\
\text { - Dinámico }\end{array}$ & $\begin{array}{l}\text { - Saltos unipodales siguiendo un } \\
\text { patrón } \\
\text { - Paciente tiene que mantener } \\
\text { todo su equilibrio }\end{array}$ \\
\hline & $\begin{array}{l}\text { Side Hop } \\
\text { Test }\end{array}$ & $\begin{array}{l}\text { Test } \\
\text { funcional }\end{array}$ & $\begin{array}{l}\text { No especifica: } \\
\text { inestabilidad crónica } \\
\text { de tobillo }\end{array}$ & $\begin{array}{l}\text { - Activo } \\
\text { - Carga } \\
\text { - Dinámico }\end{array}$ & $\begin{array}{l}\text { - Saltos en una sola extremidad de } \\
\text { medial a lateral con una distancia } \\
\text { de } 30 \mathrm{~cm} \\
\text { - } 10 \text { repeticiones }\end{array}$ \\
\hline & Foot Lift test & $\begin{array}{l}\text { Test } \\
\text { funcional }\end{array}$ & $\begin{array}{l}\text { No especifica: } \\
\text { inestabilidad crónica } \\
\text { de tobillo }\end{array}$ & $\begin{array}{l}\text { - Activo } \\
\text { - Carga } \\
\text { - Dinámico }\end{array}$ & $\begin{array}{l}\text { - Posición unipodal sobre una } \\
\text { superficie firme } \\
\text { - Levantar la extremidad tantas } \\
\text { veces como sea posible en } 30 \\
\text { segundos }\end{array}$ \\
\hline & $\begin{array}{l}\text { Star Excur- } \\
\text { sion } \\
\text { Balance Test }\end{array}$ & $\begin{array}{l}\text { Test } \\
\text { funcional }\end{array}$ & $\begin{array}{l}\text { No especifica: } \\
\text { inestabilidad crónica } \\
\text { de tobillo }\end{array}$ & $\begin{array}{l}\text { - Activo } \\
\text { - Carga } \\
\text { - Dinámico }\end{array}$ & $\begin{array}{l}\text { - Mantener el equilibrio unipodal } \\
\text { mientras se alcanzan diferentes } \\
\text { direcciones volviendo al } \\
\text { momento inicial }\end{array}$ \\
\hline $\begin{array}{l}\text { Emily y cols. } \\
(2017)^{25}\end{array}$ & Lunge Test & $\begin{array}{l}\text { Test } \\
\text { funcional }\end{array}$ & $\begin{array}{l}\text { - Gastrocnemios } \\
\text { - Sóleo } \\
\text { - Integridad } \\
\text { ligamentos del } \\
\text { tobillo }\end{array}$ & $\begin{array}{l}\text { - Activo } \\
\text { - Descarga } \\
\text { - Estático }\end{array}$ & $\begin{array}{l}\text { - Centro de talón y Hallux encima } \\
\text { cinta métrica } \\
\text { - Tocar línea de la pared sin } \\
\text { levantar pie del suelo }\end{array}$ \\
\hline
\end{tabular}


Tabla III. Descripción técnica de los test clínicos y funcionales de los artículos.

\begin{tabular}{|c|c|c|c|c|c|}
\hline $\begin{array}{l}\text { Autor } \\
\text { (año) }\end{array}$ & Test & $\begin{array}{l}\text { Tipo } \\
\text { de test }\end{array}$ & $\begin{array}{l}\text { Esctructura } \\
\text { valorada }\end{array}$ & $\begin{array}{c}\text { Modo } \\
\text { de ejecución }\end{array}$ & Realización \\
\hline \multirow{3}{*}{$\begin{array}{l}\text { Jupil y cols. } \\
(2015)^{26}\end{array}$} & Foot Lift Test & $\begin{array}{l}\text { Test } \\
\text { funcional }\end{array}$ & $\begin{array}{l}\text { No especifica: } \\
\text { inestabilidad } \\
\text { crónica de tobillo }\end{array}$ & $\begin{array}{l}\text { - Activo } \\
\text { - Carga } \\
\text { - Dinámico }\end{array}$ & $\begin{array}{l}\text { - Posición unipodal sobre una } \\
\text { superficie firme } \\
\text { - Levantar la extremidad tantas } \\
\text { veces como sea posible en } 30 \\
\text { segundos con los ojos cerrados }\end{array}$ \\
\hline & $\begin{array}{l}\text { Star } \\
\text { Excursion } \\
\text { Balance Test }\end{array}$ & $\begin{array}{l}\text { Test } \\
\text { funcional }\end{array}$ & $\begin{array}{l}\text { No especifica: } \\
\text { inestabilidad } \\
\text { crónica de tobillo }\end{array}$ & $\begin{array}{l}\text { - Activo } \\
\text { - Carga } \\
\text { - Dinámico }\end{array}$ & $\begin{array}{l}\text { - Mantener el equilibrio unipodal } \\
\text { mientras se alcanzan diferentes } \\
\text { direcciones volviendo al } \\
\text { momento inicial }\end{array}$ \\
\hline & $\begin{array}{l}\text { Single Leg } \\
\text { Hop Test }\end{array}$ & $\begin{array}{l}\text { Test } \\
\text { funcional }\end{array}$ & $\begin{array}{l}\text { No especifica: } \\
\text { inestabilidad } \\
\text { crónica de tobillo }\end{array}$ & $\begin{array}{l}\text { - Activo } \\
\text { - Carga } \\
\text { - Dinámico }\end{array}$ & $\begin{array}{l}\text { - Saltos en una sola extremidad de } \\
\text { medial a lateral con una distancia } \\
\text { de } 30 \mathrm{~cm} \\
\text { - } 10 \text { repeticiones }\end{array}$ \\
\hline \multirow{5}{*}{$\begin{array}{l}\text { Cynthia y cols. } \\
(2017)^{28}\end{array}$} & Foot Lift Test & $\begin{array}{l}\text { Test } \\
\text { funcional }\end{array}$ & $\begin{array}{l}\text { No especifica: } \\
\text { inestabilidad } \\
\text { crónica de tobillo }\end{array}$ & $\begin{array}{l}\text { - Activo } \\
\text { - Carga } \\
\text { - Dinámico }\end{array}$ & $\begin{array}{l}\text { - Posición unipodal sobre una } \\
\text { superficie firme } \\
\text { - Levantar la extremidad tantas } \\
\text { veces como sea posible en } 30 \\
\text { segundos con los ojos cerrados }\end{array}$ \\
\hline & $\begin{array}{l}\text { Time-in- Ba- } \\
\text { lance }\end{array}$ & $\begin{array}{l}\text { Test } \\
\text { funcional }\end{array}$ & $\begin{array}{l}\text { No especifica: } \\
\text { inestabilidad } \\
\text { crónica de tobillo }\end{array}$ & $\begin{array}{l}\text { - Activo } \\
\text { - Carga } \\
\text { - Dinámico }\end{array}$ & $\begin{array}{l}\text { - Posición unipodal } \\
\text { - Permanecer inmóvil posible } \\
\text { durante el mayor tiempo posible }\end{array}$ \\
\hline & $\begin{array}{l}\text { Star Ecur- } \\
\text { sion Balance } \\
\text { Test }\end{array}$ & $\begin{array}{l}\text { Test } \\
\text { funcional }\end{array}$ & $\begin{array}{l}\text { No especifica: } \\
\text { inestabilidad } \\
\text { crónica de tobillo }\end{array}$ & $\begin{array}{l}\text { - Activo } \\
\text { - Carga } \\
\text { - Dinámico }\end{array}$ & $\begin{array}{l}\text { - Mantener el equilibrio unipodal } \\
\text { mientras se alcanzan diferentes } \\
\text { direcciones volviendo al } \\
\text { momento inicial }\end{array}$ \\
\hline & $\begin{array}{l}\text { Figure of } 8 \\
\text { Hop Test }\end{array}$ & $\begin{array}{l}\text { Test } \\
\text { funcional }\end{array}$ & $\begin{array}{l}\text { No especifica: } \\
\text { inestabilidad } \\
\text { crónica de tobillo }\end{array}$ & $\begin{array}{l}\text { - Activo } \\
\text { - Carga } \\
\text { - Dinámico }\end{array}$ & $\begin{array}{l}\text { - Saltos siguiendo el patrón de la } \\
\text { Figura } 8 \\
\text { - Tan rápido como sea posible } \\
\text { - Descanso de } 1 \text { minuto entre } \\
\text { prueba }\end{array}$ \\
\hline & $\begin{array}{l}\text { Side Hop } \\
\text { Test }\end{array}$ & $\begin{array}{l}\text { Test } \\
\text { funcional }\end{array}$ & $\begin{array}{l}\text { No especifica: } \\
\text { inestabilidad } \\
\text { crónica de tobillo }\end{array}$ & $\begin{array}{l}\text { - Activo } \\
\text { - Carga } \\
\text { - Dinámico }\end{array}$ & $\begin{array}{l}\text { - Saltos en una sola extremidad de } \\
\text { medial a lateral con una distancia } \\
\text { de } 30 \mathrm{~cm} \\
\text { - } 10 \text { repeticiones }\end{array}$ \\
\hline $\begin{array}{l}\text { Thomas y cols. } \\
(2018)^{27}\end{array}$ & $\begin{array}{l}\text { Modified } \\
\text { Star Excur- } \\
\text { sion Blance } \\
\text { Test/Y- } \\
\text { Balance Test }\end{array}$ & $\begin{array}{l}\text { Test } \\
\text { funcional }\end{array}$ & $\begin{array}{l}\text { No especifica: } \\
\text { inestabilidad } \\
\text { crónica de tobillo }\end{array}$ & $\begin{array}{l}\text { - Activo } \\
\text { - Carga } \\
\text { - Dinámico }\end{array}$ & $\begin{array}{l}\text { - Mantener el equilibrio unipodal } \\
\text { mientras se alcanzan } 3 \\
\text { direcciones diferentes volviendo } \\
\text { al momento inicial } \\
\text { - } 3 \text { ciclos con descanso de } 5 \\
\text { minutos }\end{array}$ \\
\hline \multirow{4}{*}{$\begin{array}{l}\text { Cailbhe y cols. } \\
(2018)^{29}\end{array}$} & $\begin{array}{l}\text { Prueba } \\
\text { de cajón } \\
\text { anterior }\end{array}$ & $\begin{array}{l}\text { Maniobra } \\
\text { clínica }\end{array}$ & $\begin{array}{l}\text { - Subluxación } \\
\text { anterior del } \\
\text { astrágalo } \\
\text { - ATFL } \\
\end{array}$ & $\begin{array}{l}\text { - Pasivo } \\
\text { - Descarga } \\
\text { - Estático }\end{array}$ & $\begin{array}{l}\text { - Rodilla flexionada } \\
\text { - Tobillo en flexión plantar } \\
\text { - Manipulamos talón desde } \\
\text { posterior a anterior fijando tibia }\end{array}$ \\
\hline & Talar Tilt Test & $\begin{array}{l}\text { Maniobra } \\
\text { clínica }\end{array}$ & $\begin{array}{l}\text { - Inversión excesiva } \\
\text { del tobillo } \\
\text { - CFL }\end{array}$ & $\begin{array}{l}\text { - Pasivo } \\
\text { - Descarga } \\
\text { - Estático }\end{array}$ & $\begin{array}{l}\text { - Tobillo neutro } \\
\text { - Talón estable mientras se realiza } \\
\text { inversión de astrágalo y calcáneo }\end{array}$ \\
\hline & $\begin{array}{l}\text { Figure of } 8 \\
\text { Hop Test }\end{array}$ & $\begin{array}{l}\text { Test } \\
\text { funcional }\end{array}$ & $\begin{array}{l}\text { No especifica: } \\
\text { inestabilidad } \\
\text { crónica de tobillo }\end{array}$ & $\begin{array}{l}\text { - Activo } \\
\text { - Carga } \\
\text { - Dinámico }\end{array}$ & $\begin{array}{l}\text { - Saltos siguiendo el patrón de la } \\
\text { Figura } 8 \\
\text { - Tan rápido como sea posible } \\
\text { - Descanso de } 1 \text { minuto entre } \\
\text { prueba }\end{array}$ \\
\hline & Lunge Test & $\begin{array}{l}\text { Test } \\
\text { funcional }\end{array}$ & $\begin{array}{l}\text { - Gastrocnemios } \\
\text { - Sóleo } \\
\text { - Integridad } \\
\text { ligamentos del } \\
\text { tobillo }\end{array}$ & $\begin{array}{l}\text { - Activo } \\
\text { - Carga } \\
\text { - Estático }\end{array}$ & $\begin{array}{l}\text { - Centro de talón y hallux encima } \\
\text { cinta métrica } \\
\text { - Tocar línea de la pared sin } \\
\text { levantar pie del suelo }\end{array}$ \\
\hline
\end{tabular}


Tabla IV. Objetivos, test, resultados y conclusiones de los articulos a analizar.

\begin{tabular}{|c|c|c|c|c|c|}
\hline Autor (año) & Objetivo & Test & Tipo de test & Resultados & Conclusiones \\
\hline $\begin{array}{l}\text { Christophe y } \\
\text { cols. } \\
(2009)^{36}\end{array}$ & $\begin{array}{l}\text { Investigar la fiabilidad } \\
\text { y validez de un método } \\
\text { de evaluación clínica } \\
\text { para la evaluación } \\
\text { del control postural } \\
\text { dinámico en pacientes } \\
\text { con inestabilidad } \\
\text { crónica de tobillo (CAI) }\end{array}$ & $\begin{array}{l}\text { - Multiple' - Hop } \\
\text { Test }\end{array}$ & $\begin{array}{l}\text { Test } \\
\text { funcional }\end{array}$ & $\begin{array}{l}\text { La fiabilidad de la } \\
\text { prueba de repetición del } \\
\text { nombre de errores de } \\
\text { balance fue excelente } \\
\text { en los pacientes. El } \\
\text { nombre de errores de } \\
\text { equilibrio en pacientes } \\
\text { fue significativamente } \\
\text { superior en } \\
\text { comparación con } \\
\text { sujetos sanos }\end{array}$ & $\begin{array}{l}\text { La prueba de salto } \\
\text { múltiple es una } \\
\text { prueba fiable y } \\
\text { válida para detectar } \\
\text { un control postural } \\
\text { dinámico deteriorado } \\
\text { en pacientes con CAI }\end{array}$ \\
\hline $\begin{array}{l}\text { Hans y cols. } \\
(2011)^{35}\end{array}$ & $\begin{array}{l}\text { Buscar, clasificar } \\
\text { y desarrollar un } \\
\text { algoritmo para } \\
\text { el diagnóstico y } \\
\text { tratamiento de lesiones } \\
\text { agudas de tobillo }\end{array}$ & $\begin{array}{l}\text { - Prueba de cajón } \\
\text { anterior } \\
\text { - Talar tilt test } \\
\text { - Prueba de } \\
\text { rotación externa } \\
\text { - Squeeze test } \\
\text { - Prueba de } \\
\text { pierna cruzada }\end{array}$ & $\begin{array}{l}\text { Maniobra } \\
\text { clínica }\end{array}$ & $\begin{array}{l}\text { Las pruebas diagnósticas } \\
\text { dieron como resultado } \\
\text { una sensibilidad del } \\
96 \% \text { y una especificidad } \\
\text { del } 84 \% \text {. } \\
\text { Favoreciendo } \\
\text { el tratamiento } \\
\text { conservador con menos } \\
\text { complicaciones a largo } \\
\text { plazo }\end{array}$ & $\begin{array}{l}\text { El uso de este } \\
\text { algoritmo ayuda a } \\
\text { asegurar la calidad de } \\
\text { los exámenes físicos } \\
\text { para el diagnóstico de } \\
\text { lesiones para un buen } \\
\text { tratamiento en daños } \\
\text { de los tejidos blandos }\end{array}$ \\
\hline $\begin{array}{l}\text { Christophe y } \\
\text { cols. }(2012)^{34}\end{array}$ & $\begin{array}{l}\text { Determinar si la prueba } \\
\text { de salto múltiple } \\
\text { debe usarse como un } \\
\text { instrumento evaluativo } \\
\text { o discriminativo por la } \\
\text { inestabilidad crónica } \\
\text { de tobillo }\end{array}$ & $\begin{array}{l}\text { - Multiple Hop } \\
\text { Test }\end{array}$ & $\begin{array}{l}\text { Test } \\
\text { funcional }\end{array}$ & $\begin{array}{l}\text { Se obtuvieron } \\
\text { resultados positivos, } \\
\text { la sensibilidad fue del } \\
86 \% \text { y la especificidad } \\
\text { fue del } 79 \%\end{array}$ & $\begin{array}{l}\text { La prueba de Salto } \\
\text { múltiple parece ser } \\
\text { más discriminativa } \\
\text { como instrumento } \\
\text { para la inestabilidad } \\
\text { crónica de tobillo }\end{array}$ \\
\hline $\begin{array}{l}\text { Martin y cols. } \\
(2012)^{23}\end{array}$ & $\begin{array}{l}\text { Investigar la fiabilidad } \\
\text { y la validez del Lunge } \\
\text { Test comparando las } \\
\text { dos extremidades } \\
\text { inferiores para } \\
\text { determinar su impacto }\end{array}$ & - Lunge Test & $\begin{array}{l}\text { Test } \\
\text { funcional }\end{array}$ & $\begin{array}{l}\text { Los coeficientes de } \\
\text { fiabilidad fueron } \\
\text { altos, produciéndose } \\
\text { diferencias significativas } \\
\text { entre extremidades } \\
\text { sanas y dañadas }\end{array}$ & $\begin{array}{l}\text { El Lunge Test produce } \\
\text { puntuaciones fiables } \\
\text { y se considera una } \\
\text { prueba necesaria para } \\
\text { evaluar los } \\
\text { cambios de las } \\
\text { extremidades }\end{array}$ \\
\hline $\begin{array}{l}\text { Cory y cols } \\
(2013)^{5}\end{array}$ & $\begin{array}{l}\text { Determinar la fiabilidad } \\
\text { de diferentes pruebas } \\
\text { diagnósticas para la } \\
\text { entorsis de tobillo y la } \\
\text { sindesmosis }\end{array}$ & $\begin{array}{l}\text { - Prueba de cajón } \\
\text { anterior } \\
\text { - Talar tilt test } \\
\text { - Test de estrés } \\
\text { Eversión } \\
\text { - Prueba de } \\
\text { rotación externa } \\
\text { - Squeeze test }\end{array}$ & $\begin{array}{l}\text { Maniobra } \\
\text { clínica }\end{array}$ & $\begin{array}{l}\text { La fiabilidad de las } \\
\text { pruebas diagnósticas } \\
\text { fue de resultados } \\
\text { buenos en los } \\
\text { pacientes con algunas } \\
\text { controversias }\end{array}$ & $\begin{array}{l}\text { El uso de las } \\
\text { diferentes pruebas } \\
\text { diagnósticas ayuda } \\
\text { a asegurar la calidad } \\
\text { de diagnóstico y } \\
\text { tratamiento. Las } \\
\text { lesiones de bajo } \\
\text { grado responden } \\
\text { bien al tratamiento } \\
\text { conservador }\end{array}$ \\
\hline $\begin{array}{l}\text { Takumi y cols. } \\
(2014)^{24}\end{array}$ & $\begin{array}{l}\text { Proporcionar evidencia } \\
\text { científica reciente } \\
\text { sobre inestabilidad } \\
\text { crónica de tobillo, } \\
\text { incluyendo la } \\
\text { epidemiología, } \\
\text { patología y los factores } \\
\text { causales utilizando } \\
\text { distintas pruebas } \\
\text { diagnósticas }\end{array}$ & $\begin{array}{l}\text { - Prueba de cajón } \\
\text { anterior } \\
\text { - Test de } \\
\text { Romberg } \\
\text { - Star Excursion } \\
\text { Balance Test } \\
\text { (SEBT) } \\
\text { - Multiple Hop } \\
\text { Test }\end{array}$ & $\begin{array}{l}\text { Test } \\
\text { funcional/ } \\
\text { Maniobra } \\
\text { clínica }\end{array}$ & $\begin{array}{l}\text { Se obtuvieron } \\
\text { unos resultados, } \\
\text { demostrando una } \\
\text { sensibilidad del } 96 \% \text { y } \\
\text { una especificidad del } \\
84 \% \text { en las distintas } \\
\text { observaciones del } \\
\text { artículo }\end{array}$ & $\begin{array}{l}\text { La entorsis lateral de } \\
\text { tobillo es la lesión más } \\
\text { común en la mayoría } \\
\text { de los deportes, } \\
\text { proporcionando } \\
\text { en muchos de } \\
\text { estos casos una } \\
\text { inestabilidad crónica } \\
\text { de tobillo a largo plazo }\end{array}$ \\
\hline
\end{tabular}


Tabla IV. Objetivos, test, resultados y conclusiones de los articulos a analizar.

\begin{tabular}{|c|c|c|c|c|c|}
\hline Autor (año) & Objetivo & Test & Tipo de test & Resultados & Conclusiones \\
\hline $\begin{array}{l}\text { Alex y cols. } \\
(2015)^{22}\end{array}$ & $\begin{array}{l}\text { El objetivo es revisar } \\
\text { las pruebas clínicas } \\
\text { y diagnósticas de las } \\
\text { lesiones de tobillo e } \\
\text { iniciar un diagnóstico } \\
\text { y tratamiento correcto } \\
\text { para la lesión }\end{array}$ & $\begin{array}{l}\text { - Prueba de } \\
\text { rotación externa } \\
\text { - Squeeze test } \\
\text { - Prueba de } \\
\text { algodón } \\
\text { - Prueba de } \\
\text { traducción } \\
\text { fibular } \\
\text { - Prueba de cajón } \\
\text { anterior } \\
\text { - Talar Tilt Test } \\
\text { - Test de } \\
\text { Thompson }\end{array}$ & $\begin{array}{l}\text { Maniobra } \\
\text { clínica }\end{array}$ & $\begin{array}{l}\text { Hay poco acuerdo sobre } \\
\text { la fiabilidad de algunas } \\
\text { pruebas. Se necesita } \\
\text { investigación para } \\
\text { desarrollar un mejor } \\
\text { método para clasificar la } \\
\text { entorsis lateral de tobillo }\end{array}$ & $\begin{array}{l}\text { La mayoría de } \\
\text { las lesiones } \\
\text { musculoesqueléticas } \\
\text { pueden ser } \\
\text { diagnosticadas por } \\
\text { la historia clínica; } \\
\text { cuando no es } \\
\text { suficiente incluirá la } \\
\text { evaluación clínica } \\
\text { observando las } \\
\text { limitaciones de las } \\
\text { pruebas }\end{array}$ \\
\hline $\begin{array}{l}\text { Michael y cols. } \\
(2015)^{33}\end{array}$ & $\begin{array}{l}\text { Determinar la fuerza, } \\
\text { rango de movimiento } \\
\text { de dorsiflexión, } \\
\text { sensación cutánea } \\
\text { plantar y control } \\
\text { postural estático } \\
\text { para el examen } \\
\text { de equilibrio de la } \\
\text { excursión en estrella } \\
\text { en el rendimiento } \\
\text { de pacientes con } \\
\text { inestabilidad crónica } \\
\text { de tobillo }\end{array}$ & $\begin{array}{l}\text { - Star Excursion } \\
\text { Balance Test }\end{array}$ & $\begin{array}{l}\text { Test } \\
\text { funcional }\end{array}$ & $\begin{array}{l}\text { Las diferentes } \\
\text { direcciones de la } \\
\text { excursión en estrella } \\
\text { produjeron modelos } \\
\text { clínicamente relevantes }\end{array}$ & $\begin{array}{l}\text { Las estrategias de } \\
\text { rehabilitación de la } \\
\text { prueba de excursión } \\
\text { en estrella deben } \\
\text { enfatizar el rango } \\
\text { de movimiento, } \\
\text { sensaciones cutáneas, } \\
\text { fuerza en eversión } \\
\text { y equilibrio estático } \\
\text { para mejorar el control } \\
\text { postural dinámico } \\
\text { en pacientes con } \\
\text { inestabilidad crónica } \\
\text { de tobillo }\end{array}$ \\
\hline $\begin{array}{l}\text { Amy y cols. } \\
(2015)^{32}\end{array}$ & $\begin{array}{l}\text { Investigar la precisión } \\
\text { de diagnóstico } \\
\text { clínico de diferentes } \\
\text { pruebas clínicas } \\
\text { comunes }\end{array}$ & $\begin{array}{l}\text { - Prueba de } \\
\text { rotación externa } \\
\text { - Squeeze test } \\
\text { - Palpación } \\
\text { ligamentosa }\end{array}$ & $\begin{array}{l}\text { Maniobra } \\
\text { clínica/Test } \\
\text { funcional }\end{array}$ & $\begin{array}{l}\text { Los resultados } \\
\text { obtenidos en la } \\
\text { investigación de las } \\
\text { diferentes pruebas } \\
\text { clínicas demostraron } \\
\text { una sensibilidad de } \\
84 \% \text { y una especificidad } \\
\text { del } 83,5 \%\end{array}$ & $\begin{array}{l}\text { Según el artículo } \\
\text { ninguna prueba es } \\
\text { suficientemente } \\
\text { precisa para el } \\
\text { diagnóstico de las } \\
\text { lesiones de tobillo. } \\
\text { Recomendando la } \\
\text { combinación de } \\
\text { signos, síntomas y } \\
\text { pruebas específicas } \\
\text { y sensibles para } \\
\text { confirmar la lesión }\end{array}$ \\
\hline $\begin{array}{l}\text { Lars y cols. } \\
(2016)^{31}\end{array}$ & $\begin{array}{l}\text { Evaluar la incidencia de } \\
\text { lesiones sindesmóticas } \\
\text { en entorsis aguda de } \\
\text { tobillo para determinar } \\
\text { la precisión de pruebas } \\
\text { diagnósticas clínicas } \\
\text { comunes para analizar } \\
\text { especificidad }\end{array}$ & $\begin{array}{l}\text { - Prueba de cajón } \\
\text { anterior } \\
\text { - Squeeze test } \\
\text { - Prueba de } \\
\text { rotación externa } \\
\text { - Prueba de } \\
\text { algodón } \\
\text { - Prueba de la } \\
\text { pierna cruzada }\end{array}$ & $\begin{array}{l}\text { Maniobra } \\
\text { clínica/Test } \\
\text { funcional }\end{array}$ & $\begin{array}{l}\text { Todas las pruebas } \\
\text { clínicas demostraron } \\
\text { tener una alta } \\
\text { fiabilidad, pero una } \\
\text { baja sensibilidad. Se } \\
\text { encontraron valores } \\
\text { de todas las pruebas } \\
\text { clínicas de } 13.9-55.6 \%\end{array}$ & $\begin{array}{l}\text { En este estudio el } \\
\text { examen clínico fue } \\
\text { insuficiente para } \\
\text { detectar lesiones } \\
\text { sindesmóticas en } \\
\text { entorsis aguda de } \\
\text { tobillo }\end{array}$ \\
\hline $\begin{array}{l}\text { Adam y cols. } \\
(2017)^{30}\end{array}$ & $\begin{array}{l}\text { Determinar la } \\
\text { efectividad de } \\
\text { pruebas funcionales } \\
\text { para diferenciar la } \\
\text { inestabilidad crónica } \\
\text { de tobillo }\end{array}$ & $\begin{array}{l}\text { - Multiple-hop } \\
\text { test } \\
\text { - Side-hop test } \\
\text { - Foot-lift test } \\
\text { - Star Excursion } \\
\text { Balance Test }\end{array}$ & $\begin{array}{l}\text { Test } \\
\text { funcional }\end{array}$ & $\begin{array}{l}\text { Los estudios incluidos } \\
\text { se evaluaron según la } \\
\text { calidad metodológica } \\
\text { y el nivel de evidencia. } \\
\text { Diferentes pruebas de } \\
\text { rendimiento funcional } \\
\text { demostraron muy } \\
\text { buena utilidad }\end{array}$ & $\begin{array}{l}\text { Hubo un alto grado } \\
\text { de heterogeneidad } \\
\text { en la implantación } \\
\text { de las diferentes } \\
\text { pruebas. Son pruebas } \\
\text { baratas y efectivas } \\
\text { comparadas con las } \\
\text { instrumentadas }\end{array}$ \\
\hline
\end{tabular}


Tabla IV. Objetivos, test, resultados y conclusiones de los articulos a analizar.

\begin{tabular}{|c|c|c|c|c|c|}
\hline Autor (año) & Objetivo & Test & Tipo de test & Resultados & Conclusiones \\
\hline $\begin{array}{l}\text { Emily y cols. } \\
(2017)^{25}\end{array}$ & $\begin{array}{l}\text { Determinar la validez } \\
\text { de resultados clínicos } \\
\text { del Lunge desde } \\
\text { diferentes ángulos } \\
\text { para evaluar el rango } \\
\text { de movimiento en } \\
\text { dorsiflexión }\end{array}$ & - Lunge Test & $\begin{array}{l}\text { Test } \\
\text { funcional }\end{array}$ & $\begin{array}{l}\text { Hubo una alta } \\
\text { correlación entre las } \\
\text { diferentes mediciones }\end{array}$ & $\begin{array}{l}\text { Este estudio } \\
\text { determinó que las } \\
\text { medidas clínicas } \\
\text { utilizadas durante } \\
\text { el Lunge Test tienen } \\
\text { una alta correlación } \\
\text { para evaluar el rango } \\
\text { de movimiento en } \\
\text { dorsiflexión }\end{array}$ \\
\hline $\begin{array}{l}\text { Jupil y cols. } \\
(2017)^{26}\end{array}$ & $\begin{array}{l}\text { Determinar si una sola } \\
\text { o/y combinación de } \\
\text { pruebas clínicas son } \\
\text { válidas para valorar la } \\
\text { entorsis de tobillo }\end{array}$ & $\begin{array}{l}\text { - Foot Lift Test } \\
\text { - Star Excursion } \\
\text { Balance Test } \\
\text { - Single-Leg Hop } \\
\text { Test }\end{array}$ & $\begin{array}{l}\text { Test } \\
\text { funcional }\end{array}$ & $\begin{array}{l}\text { La combinación } \\
\text { de pruebas dio } \\
\text { un resultado } \\
\text { significativamente } \\
\text { bueno, predominando } \\
\text { Single Leg Hop Test y } \\
\text { Star Excursion Balance } \\
\text { test }\end{array}$ & $\begin{array}{l}\text { Usar múltiples } \\
\text { pruebas es de } \\
\text { ayuda para un } \\
\text { buen diagnóstico. } \\
\text { El uso de Single } \\
\text { Leg Hop Test y Star } \\
\text { Excursión Balance } \\
\text { test resultó un mejor } \\
\text { reconocimiento de } \\
\text { los pacientes con } \\
\text { inestabilidad } \\
\text { crónica de tobillo }\end{array}$ \\
\hline $\begin{array}{l}\text { Cynthia y cols. } \\
(2017)^{28}\end{array}$ & $\begin{array}{l}\text { Evaluar la eficacia } \\
\text { comparativa de } \\
\text { diferentes técnicas } \\
\text { comunes de } \\
\text { rehabilitación del } \\
\text { tobillo }\end{array}$ & $\begin{array}{l}\text { - Foot lift test } \\
\text { - Time-in-balance } \\
\text { - Star Excursion } \\
\text { Balance Test } \\
\text { - Figure of } 8 \text { Hop } \\
\text { Test } \\
\text { - Side-Hop Test }\end{array}$ & $\begin{array}{l}\text { Test } \\
\text { funcional }\end{array}$ & $\begin{array}{l}\text { Hubo mejoras } \\
\text { significativas después } \\
\text { de las distintas técnicas } \\
\text { aplicadas en los } \\
\text { pacientes }\end{array}$ & $\begin{array}{l}\text { La evidencia indica } \\
\text { que el entrenamiento } \\
\text { de las distintas } \\
\text { pruebas es efectivo } \\
\text { después de pocas } \\
\text { sesiones }\end{array}$ \\
\hline $\begin{array}{l}\text { Thomas y cols. } \\
(2018)^{27}\end{array}$ & $\begin{array}{l}\text { Evaluar el equilibrio } \\
\text { dinámico bajo } \\
\text { condiciones de carga }\end{array}$ & $\begin{array}{l}\text { - } \text { Modified Star } \\
\text { Excursion } \\
\text { Balance Test/Y- } \\
\text { Balance Test }\end{array}$ & $\begin{array}{l}\text { Test } \\
\text { funcional }\end{array}$ & $\begin{array}{l}\text { Los participantes } \\
\text { tuvieron distancias de } \\
\text { alcance lateral posterior } \\
\text { significativamente más } \\
\text { cortas }\end{array}$ & $\begin{array}{l}\text { La carga afectó } \\
\text { significativamente el } \\
\text { equilibrio dinámico }\end{array}$ \\
\hline $\begin{array}{l}\text { Cailbhe y cols. } \\
(2018)^{29}\end{array}$ & $\begin{array}{l}\text { Evaluar si diferentes } \\
\text { pruebas clínicas } \\
\text { pueden ser útiles } \\
\text { para predecir la } \\
\text { recuperación a largo } \\
\text { plazo }\end{array}$ & $\begin{array}{l}\text { - Prueba de cajón } \\
\text { anterior } \\
\text { - Talar Tilt Test } \\
\text { - Figure of } 8 \text { hop } \\
\text { test } \\
\text { - Lunge Test }\end{array}$ & $\begin{array}{l}\text { Test } \\
\text { funcional }\end{array}$ & $\begin{array}{l}\text { Los resultados finales } \\
\text { de las distintas pruebas } \\
\text { clínicas tuvieron una } \\
\text { sensibilidad moderada } \\
\text { del } 64 \% \text { y buena } \\
\text { especificidad de } 72 \%\end{array}$ & $\begin{array}{l}\text { Las pruebas clínicas } \\
\text { utilizadas en esta } \\
\text { investigación tienen } \\
\text { un valor predictivo } \\
\text { limitado para la } \\
\text { inestabilidad crónica } \\
\text { de tobillo cuando } \\
\text { se realiza en la fase } \\
\text { aguda }\end{array}$ \\
\hline
\end{tabular}

\section{DISCUSIÓN}

En general, todos los artículos obtienen una alta fiabilidad de las diferentes maniobras clínicas que se realizan en cada caso, exceptuando Amy y cols. ${ }^{32}$, Lars y cols. ${ }^{31}$, Cailbhe y cols. ${ }^{29}$, donde dicen que las maniobras clínicas utilizadas son insuficientes y limitadas para un correcto diagnóstico, teniendo que complementarlas con otras pruebas más específicas y sensibles para confirmar la lesión de entorsis de tobillo.
Todos los autores coinciden en general con la aplicación y realización de maniobras clínicas o pruebas funcionales. La prueba utilizada con más frecuencia es el de cajón anterior $5,22,24,29,31,35$, seguido de la prueba de rotación externa $\mathrm{n}^{522,31,32,35}$, Star Excursion Balance Test ${ }^{24,26,28,30,33}$, Squeeze Test ${ }^{5,22,31,33,35}$, Multiple Hop Test ${ }^{24,30,34,36}$, Talar Tilt Test ${ }^{5,22,29,35}$, Lunge Test ${ }^{23,25,29}$, Side/Single Hop Test ${ }^{26,28,30}$, Foot lift test ${ }^{26,28,30}$, prueba de la pierna cruzada ${ }^{31,35}$, prueba de algodón ${ }^{22,31}$ y figure of 8 hop test ${ }^{28,29}$, test de estrés en eversión ${ }^{5}$, test de Rom- 
berg $^{24}$, test de Y-Balance ${ }^{27}$, prueba de traducción fibular ${ }^{22}$, test de Thompson ${ }^{22}$ y Time in Balance ${ }^{28}$.

Martin y cols. ${ }^{23}$, Takumi y cols. ${ }^{24}$, Alex y cols. ${ }^{22}$, Michael y cols. ${ }^{33}$, Amy y cols..$^{32}$, Emily y cols. ${ }^{25}$, Cailbhe y cols. ${ }^{29}$ son los únicos, comparados con el resto de autores, que en sus artículos muestran los síntomas principales que padecen los pacientes para la aplicación de las maniobras clínicas durante el diagnóstico.

Thomas y cols. ${ }^{27}$, comparado con los autores Takumi y cols. ${ }^{24}$, Michael y cols. ${ }^{33}$, Adam y cols. ${ }^{30}$, Jupil y cols. ${ }^{26}$, Cynthia y cols. ${ }^{28}$, describen el Y-Balance Test como a la modificación del Star Excursion Balance Test. A diferencia de este último, el Y-Balance Test evalúa el equilibrio dinámico en solo tres direcciones: anterior, medial-posterior y lateral-posterior, requiriendo que el paciente se pare en el centro de una rejiIla colocada en el suelo con tres líneas de alcance en forma de una Y. De esta forma se mide la fuerza, la estabilidad y el equilibrio del paciente en varias direcciones, estandarizando la prueba Star Excursion Balance Test.

Las prueba de cajón anterior $5,22,24,29,31,35$, Talar Tilt Test $^{5,22,29,35}$, prueba de rotación externa $a^{5,22,31,32,35}$, Squeeze Test $^{5,22,31,33,35}$, prueba de la pierna cruzada ${ }^{31,35}$, prueba de algodón ${ }^{22,31}$, test de estrés en eversión ${ }^{5}$, prueba de traducción fibular ${ }^{22}$ y test de Thompson ${ }^{22}$ están clasificados como maniobras clínicas y el Multiple Hop Test ${ }^{24,30,34,36}$, Lunge Test ${ }^{23,25,29}$, test de Romberg ${ }^{24}$, Star Excursion Balance Test $^{24,26,28,30,33}$, Y-Balance Test ${ }^{27}$, Side/Single Hop Test ${ }^{26,28,30}$, Foot Lift Test ${ }^{26,28,30}$, Time in Balance ${ }^{28}$ y figure of 8 Hop Test $^{28,29}$ como pruebas funcionales.

Una buena clasificación de las maniobras clínicas es útil para un diagnóstico preciso a la hora de la lesión, mientras que las pruebas funcionales son útiles para observar y valorar la lesión a largo plazo de la inestabilidad crónica de tobillo.

Finalmente, solo Amy y cols..$^{32}$ utilizan la palpación ligamentosa complementada durante la realización de otras maniobras clínicas para así tener más precisión a la hora de hacer un buen diagnóstico y tratamiento.

A través de esta revisión de la literatura es posible concluir que las maniobras clínicas después de su descripción son útiles para diagnosticar la entorsis de tobillo.

En muchos casos es muy frecuente la inestabilidad crónica de tobillo, donde es importante un buen tratamiento para intentar disminuir la impotencia funcional del paciente y obtener una mejora.

En general, la entorsis de tobillo es una lesión muy frecuente, en concreto en personas que practican deporte. Por este motivo es de gran importancia plasmar una buena prevención y, en caso de lesión, una buena recuperación a la hora de volver a la actividad física, ya que es muy frecuente la entorsis de repetición y estos casos proporcionan mayor dificultad de recuperación.

Por último, podemos afirmar que es una lesión muy extensa y que necesita un tratamiento prolongado. El uso de múltiples pruebas es básico y fundamental para un buen diagnóstico de la lesión.

\section{CONFLICTO DE INTERESES}

Los autores declaran no tener ningún conflicto de interés.

\section{FINANCIACIÓN}

Esta investigación no ha tenido fuente de financiación.

\section{BIBLIOGRAFÍA}

1. Hertel J. Functional anatomy, pathomechanics, and pathophysiology of lateral ankle instability. J Athl Train. 2002;37(4):364-75.

2. Cimolin V, Galli M. Summary measures for clinical gait analysis: A literature review. Gait Posture. 2014;39(4):1005-10. DOI: 10.1016/j.gaitpost.2014.02.001.

3. Delahunt E, Bleakley CM, Bossard DS, Caulfield BM, Docherty CL, Doherty $C$, et al. Clinical assessment of acute lateral ankle sprain injuries (ROAST): 2019 consensus statement and recommendations of the International Ankle Consortium. Br J Sport Med. 2018;52(20):1304-10. DOI: 10.1136/bjsports-2017-098885.

4. Walker J. Assessment and management of patients with ankle injuries. Nurs Stand. 2014;28(50):52-9. DOI: 10.7748/ns.28.50.52.e9128.

5. Czajka CM, Tran E, Cai AN, DiPreta JA. Ankle Sprains and Instability. Med Clin North Am. 2014;98(2):313-29. DOI: 10.1016/j.mcna.2013.11.003.

6. Hiller CE, Nightingale EJ, Raymond J, Kilbreath SL, Burns J, Black DA, et al. Prevalence and Impact of Chronic Musculoskeletal Ankle Disorders in the Community. Arch Phys Med Rehabil. 2012;93(10):1801-7. DOI: 10.1016/j.apmr.2012.04.023.

7. Shah S, Thomas AC, Noone JM, Blanchette CM, Wikstrom EA. Incidence and Cost of Ankle Sprains in United States Emergency Departments. Sport Health. 2016;8(6):547-52.

8. Doherty C, Delahunt E, Caulfield B, Hertel J, Ryan J, Bleakley C. The Incidence and Prevalence of Ankle Sprain Injury: A Systematic Review and Meta-Analysis of Prospective Epidemiological Studies. Sport Med. 2014;44(1):123-40. DOI: 10.1007/s40279-013-0102-5.

9. Golanó P, Vega J, de Leeuw PAJ, Malagelada F, Manzanares MC, Götzens $V$, et al. Anatomy of the ankle ligaments: a pictorial essay. Knee Surg Sports Traumatol Arthrosc. 2010;18(5):557-69. DOI: 10.1007/ s00167-010-1100-x

10. Bulathsinhala L, Hill OT, Scofield DE, Haley TF, Kardouni JR. Epidemiology of Ankle Sprains and the Risk of Separation From Service in US Army Soldiers. J Orthop Sport Phys Ther. 2015;45(6):477-84. DOI: 10.2519/ jospt.2015.5733.

11. Waterman CBR, Owens MBD, Davey CS, Zacchilli CMA, Belmont LCPJ. The Epidemiology of Ankle Sprains in the United States. J Bone Joint Surg Am. Vol. 2010;92(13):2279-84

12. Pourkazemi F, Hiller CE, Raymond J, Nightingale EJ, Refshauge KM. Predictors of chronic ankle instability after an index lateral ankle sprain: A systematic review. J Sci Med Sport. 2014;17(6):568-73. DOI: 10.1016/j. jsams.2014.01.005.

13. Vega J, Malagelada F, Manzanares Céspedes MC, Dalmau-Pastor M. The lateral fibulotalocalcaneal ligament complex: an ankle stabilizing isometric structure. Knee Surg Sports Traumatol Arthrosc. 2018. DOI: 10.1007/s00167-018-5188-8.

14. Bozkurt M, Doral MN. Anatomic Factors and Biomechanics in Ankle Instability. Foot Ankle Clin. 2006;11(3):451-63. DOI: 10.1016/j. fcl.2006.06.001.

15. Willems TM, Witvrouw E, Delbaere K, Mahieu N, De Bourdeaudhuij I, De Clercq D. Intrinsic risk factors for inversion ankle sprains in male subjects: a prospective study. Am J Sports Med. 2005;33(3):415-23. DOI: $10.1177 / 0363546504268137$.

16. Zalavras C, Thordarson D. Ankle syndesmotic injury. J Am Acad Orthop Surg. 2007; 15(6):330-9.

17. Perry J, Burnfield JM, Cabico LM. Gait analysis: normal and pathological function. New Jersey: SLACK; 2010. 
18. Kerkhoffs GM, van den Bekerom M, Elders LAM, van Beek PA, Hullegie WAM, Bloemers GMFM, et al. Diagnosis, treatment and prevention of ankle sprains: an evidence-based clinical guideline. Br J Sports Med. 2012;46(12):854-60. DOI: 10.1136/bjsports-2011-090490.

19. Liberati A, Altman DG, TetzlaffJ, Mulrow C, Gøtzsche PC, loannidisJPA, etal. The PRISMA statement for reporting systematic reviews and meta- analyses of studies that evaluate healthcare interventions: explanation and elaboration. BMJ. 2009;339(jul21 1):b2700. DOI: 10.1136/bmj.b2700.

20. Stewart LA, Clarke M, Rovers M, Riley RD, Simmonds M, Stewart G, et al. Preferred Reporting Items for a Systematic Review and Meta-analysis of Individual Participant Data. JAMA. 2015;313(16):1657-65. DOI: 10.1001/jama.2015.3656.

21. Harris RP, Helfand M, Woolf SH, Lohr KN, Mulrow CD, Teutsch SM, et al. Current methods of the US Preventive Services Task Force: a review of the process. Am J Prev Med. 2001;20(3 Suppl):21-35.

22. Kor A. Dynamic Techniques for Clinical Assessment of the Athlete. Clin Podiatr Med Surg. 2015;32(2):217-29. DOI: 10.1016/j. cpm.2014.11.004.

23. Chisholm MD, Birmingham TB, Brown J, MacDermid J, Chesworth BM. Reliability and Validity of a Weight-Bearing Measure of Ankle Dorsiflexion Range of Motion. Physiother Canada. 2012;64(4):347-55.

24. Kobayashi T, Gamada K. Lateral Ankle Sprain and Chronic Ankle Instability: A Critical Review. Foot Ankle Spec. 2014;7(4):298-326. DOI: 10.1177/1938640014539813.

25. Hall EA, Docherty CL. Validity of clinical outcome measures to evaluate ankle range of motion during the weight-bearing lunge test. J Sci Med Sport. 2017;20(7):618-21. DOI: 10.1016/j.jsams.2016.11.001.

26. KoJ, Rosen AB, Brown CN. Comparison Between Single and Combined Clinical Postural Stability Tests in Individuals With and Without Chronic Ankle Instability. Clin J Sport Med. 2017;27(4):394-9. DOI: 10.1097/ JSM.0000000000000354.

27. Denehey T, Marshall T, Spaccarotella K, Andzel W. The Impact of an External Load of Football Equipment on Dynamic Balance as Assessed by the Modified Star Excursion Balance Test. Int J Exerc Sci. 2018;11(4):797-805.
28. Wright CJ, Linens SW, Cain MS. A Randomized Controlled Trial Comparing Rehabilitation Efficacy in Chronic Ankle Instability. J Sport Rehabil. 2017;26(4):238-49. DOI: 10.1123/jsr.2015-0189.

29. Doherty C, Bleakley C, Hertel J, Caulfield B, Ryan J, Delahunt E. Clinical Tests Have Limited Predictive Value for Chronic Ankle Instability When Conducted in the Acute Phase of a First-Time Lateral Ankle Sprain Injury. Arch Phys Med Rehabil. 2018;99(4):720-5.e1. DOI: 10.1016/j. apmr.2017.11.008.

30. Rosen AB, Needle AR, Ko J. Ability of Functional Performance Tests to Identify Individuals With Chronic Ankle Instability. Clin J Sport Med. 2017. DOI: 10.1097/JSM.0000000000000535.

31. Großterlinden LG, Hartel M, Yamamura J, Schoennagel B, Bürger N, Krause $M$, et al. Isolated syndesmotic injuries in acute ankle sprains: diagnostic significance of clinical examination and MRI. Knee Surgery, Sport Traumatol Arthrosc. 2016;24(4):1180-6. DOI: 10.1007/s00167015-3604-x.

32. Sman AD, Hiller CE, Rae K, Linklater J, Black DA, Nicholson LL, et al. Diagnostic accuracy of clinical tests for ankle syndesmosis injury. $\mathrm{Br}$ J Sports Med. 2015;49(5):323-9. DOI: 10.1136/bjsports-2013-092787.

33. Gabriner ML, Houston MN, Kirby JL, Hoch MC. Contributing factors to star excursion balance test performance in individuals with chronic ankle instability. Gait Posture. 2015;41(4):912-6. DOI: 10.1016/j.gaitpost.2015.03.013.

34. Eechaute C, Bautmans I, De Hertogh W, Vaes P. The Multiple Hop Test. Clin J Sport Med. 2012;22(3):228-33. DOI: 10.1097/JSM. Ob013e31824a5761.

35. Polzer H, Kanz KG, Prall WC, Haasters F, Ockert B, Mutschler W, et al. Diagnosis and treatment of acute ankle injuries: development of an evidence-based algorithm. Orthop Rev (Pavia). 2011;4(1):5. DOI: 10.4081/or.2012.e5.

36. Eechaute C, Vaes P, Duquet W. The Dynamic Postural Control Is Impaired in Patients with Chronic Ankle Instability: Reliability and Validity of the Multiple Hop Test. Clin J Sport Med. 2009;19(2):107-14. DOI: 10.1097/JSM.0b013e3181948ae8. 